\title{
An Available-to-Promise Allocation Decision Model Based on Assemble-to-Order Supply Chain
}

\author{
Manxue Xu, Huaili Chen \\ Institute of Logistics Science and Engineering, Shanghai Maritime University, Shanghai, China \\ Email:Th2020Xue@163.com
}

How to cite this paper: Xu, M.X. and Chen, H.L. (2019) An Available-to-Promise Allocation Decision Model Based on Assemble-to-Order Supply Chain. American Journal of Industrial and Business Management, 9, 1475-1485.

https://doi.org/10.4236/ajibm.2019.96097

Received: May 27, 2019

Accepted: June 27, 2019

Published: June 30, 2019

Copyright $\odot 2019$ by author(s) and Scientific Research Publishing Inc. This work is licensed under the Creative Commons Attribution International License (CC BY 4.0).

http://creativecommons.org/licenses/by/4.0/

\begin{abstract}
The main content of this research is about the ATP (Available to promise) allocation problem based on Assemble-to-Order Supply Chain. In the case of Multiple-Suppliers, the synchronous planning method is selected to discuss the supply plan and demand plan and an ATP allocation decision model adapted to ATO supply chain production environment is established. Based on the equal-weight combination forecasting method, the forecast demand was input into the ATP distribution model. The mixed integer linear programming method was adopted to solve the calculation and analyze the cost and benefit. Finally, the optimal ATP distribution scheme was obtained.
\end{abstract}

\section{Keywords}

ATO Supply Chain, ATP, Combination Forecast Method, Allocation

Decision

\section{Introduction}

In today's competitive market, the importance of customers is attracting more and more attention from companies. How to maintain the relationship with key customers has become an important part of enterprise development. As a principle in the supply chain, the accurate and timely commitment of production enterprises to orders has become one of the important indicators to measure their competitiveness. The factors that affect the timely delivery of enterprises mainly come from the uncertainty of the supply chain. In order to reduce the loss caused by the failure to fulfill orders on time caused by the uncertainty, it is necessary to allocation in advance the enterprise's supply chain ATP (Available to Promise). 
Manufacturers are focusing on ATP as a retention strategy, in which they are forced to promise customers in advance how many they can deliver on a given delivery date. [1] takes the normal available capacity, overtime available capacity and external available resources of an enterprise as the ATP of the enterprise, and establish the decision-making model of ATP cost allocation. [2] focuses on the multiple-product ATP (MATP) strategy to maximize the manufacturer's net profit. [3] establishes a flexible order configuration model for ATO supply chain by proposing an order configuration strategy combining secondary delivery and substitution. [4] uses a dynamic short-term pseudo-order prediction to manage a promising assembly system. And [5] studies the supply chain commitment allocation problem based on customer classification. [6] proposes an ATP model that considers two factors: customer priority and variance of penalty cost. [7] studies how to enhance the robustness of commitment ability. [8] studies the commitment model of periodic order commitment and propose a dynamic order resource retention strategy. [9] attempts to solve the dynamic order commitment problem and establish a mixed integer programming model with fuzzy constraints. [10] proposes a promising (ATP) model supporting TFT-LCD manufacturing order execution process decision. [11] proposes a mathematical planning and ordering model from LHP production to inventory environment [12] studies the rationing of common components among multiple products in the order-configured system under the uncertainty of order configuration. [13] proposes a mathematical model for processing heterogeneous ATP in fruit Supply Chains and a pricing strategy based on product SL at delivery. [14] discusses the advanced commitment availability (AATP) in the assembly line scheduling problem of mixed model.

To sum up, although some studies have been conducted on the issue of allocation in advance of commitments, the practicability is not too high and is based on the single component supply source. On this basis, this paper establishes a commitment allocation decision model adapted to ATO supply chain production environment under the condition of multiple supply sources of components. Based on the combination forecasting method of customer demand forecasting, the forecast demand is incorporated into the ATP allocation model. The solution is solved by mixed integer linear programming to find the solution with the maximum profit. However, the allocation of Available to Promise in this paper takes ATO type production enterprises in a single channel supply chain environment as the research object, so as to conduct modeling and quantitative research. However, it is not suitable for ATO type production enterprises in the environment of dual-channel supply chain. Nevertheless, this paper is of great reference value to ATO type production enterprises in terms of Available to Promise allocation.

\section{Materials and Methods}

\subsection{Problem Description}

In ATO supply chain, the final assembly process of products is driven by cus- 
tomer orders to meet the personalized needs of customers. In the process of customers placing orders and receiving goods, the manufacturer only carries out the final assembly process of the products, which greatly shortens the production time of the products and realizes customers' requirement of rapid delivery. However, the subsequent limitation of assembly process production capacity and material supply capacity has become a new problem for ATO supply chain manufacturers to achieve market supply and demand balance and improve customer service level. Therefore, this paper expects to solve the problem of rational allocation of resources under the condition of short supply by studying the ATP allocation problem of ATO type production enterprises, so as to improve the response speed of supply chain and make reliable order fulfillment commitment.

Based on the above description, the problem can be reduced to the scenario described in Figure 1. The figure shows an assembly-type manufacturing enterprise with multiple suppliers and one factory that can produce different types of products. Because each component has multiple suppliers, each product has multiple customers, and the lead time of enterprise assembly products is very short, enterprises need to adopt ATO supply chain production operation mode. According to the forecast, the assembled product components are ordered by providing each supplier with a purchase order in advance and produced and assembled according to the customer order.

\subsection{Available-to-Promise Allocation Decision Model}

\subsubsection{Customer Demand Forecast}

In order to improve the accuracy of customer demand forecasting, this paper adopts the equal-weight combination forecasting method which is composed of two forecasting methods commonly used in current production enterprises, namely quadratic moving average method and quadratic exponential smoothing method. And are the predicted values of the quadratic moving average method and the quadratic exponential smoothing method in the period $t$, respectively. The predicted results of the two prediction methods are combined into the new

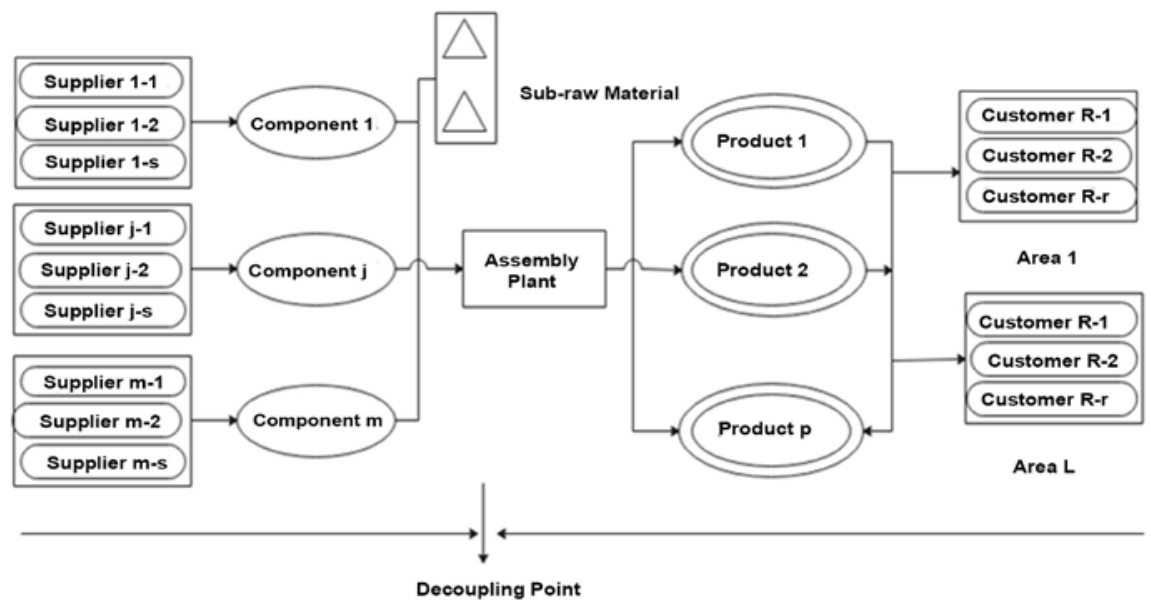

Figure 1. Flow chart of ATO supply chain manufacturer. 
predicted values according to the same weight $w_{i}=0.5(i=1,2)$. The weight combination prediction model formula is like the follows:

$$
S_{T}=0.5 S_{1(t+T)}+0.5 S_{2(t+T)}
$$

\subsubsection{Assumptions and Notations Description}

Assumptions the goal of ATO supply chain ATP configuration decision is to achieve maximum profit while responding quickly to customer orders and timely fulfilling the contract. The supply chain in this article consists of three members: a set of suppliers, a factory, and a set of customers. In order to facilitate the solution and study the relationship between ATP configuration and related costs and other parameters through calculation results, this model has the following assumptions. It is assumed that the component supply capacity, order cost, purchase cost, product supply price, product and component inventory cost and product transportation cost of each supplier will remain unchanged for a period of time in the future. The production lead time is zero, and the production capacity and the product component supply capacity are limited. Components are available at the beginning of each period. The same component manufacturer can order from multiple suppliers and bear the corresponding costs. Manufacturers offer different prices for different levels of customers in different regions. The cost of preparation for production is ignored; Historical sales data are available. The storage capacity and transportation capacity of the enterprise is unlimited. The safety inventory of finished products and components is ignored. Production and consumption are synchronized, and no extra production is produced. The input data in the model, such as price, cost, component supply capacity, production capacity and product BOM table, has been obtained. Material transportation cost shall be borne by the material supplier. Suppose that at the end of each period, the factory distributes goods to the customer. Table 1 describes the notations related to the parameters and decisions variables of the proposed models.

\section{Objective Function}

$$
\begin{aligned}
\max Y= & \sum_{t \in T} \sum_{l \in L} \sum_{r \in R} \sum_{t \geq t} \sum_{p \in P}\left(Q_{t l r \tau p}^{(p)} \cdot P_{t l r p}^{(p)}\right)-\sum_{t \in T} \sum_{m \in M} C_{m}^{(h)} \cdot\left(\frac{B_{t m}^{(m)}+E_{t m}^{(m)}}{2}\right) \\
& -\sum_{t \in T} \sum_{p \in P}\left(C_{p}^{(h)} \cdot E_{t p}^{(p)}\right)-\sum_{t \in T} \sum_{p \in P}\left(C_{t p}^{(p)} \cdot Q_{t p}^{(p)}\right) \\
& -\sum_{t \in T} \sum_{l \in L} \sum_{r \in R} \sum_{\tau \geq t} \sum_{p \in P}\left(Q_{t l r \tau p}^{(p)} \cdot C_{l p}^{(d)}\right) \\
& -\sum_{t \in T} \sum_{m \in M} \sum_{s \in S}\left(P_{t m s}^{(m)} \cdot Q_{t m s}^{(m)}\right)-\sum_{t \in T} \sum_{m \in M} \sum_{s \in S}\left(C_{t m s}^{(o)} \cdot y_{t m s}^{(m)}\right)
\end{aligned}
$$

Objective function means total income minus material inventory cost, product inventory cost, product production cost, product transportation cost, material purchase cost and material order cost.

Constraint Condition 1: First the paper will give some Capacity constraints as follows.

$$
\sum_{p \in P} Q_{t p}^{(p)} \cdot u_{p}^{\left(c^{\prime}\right)} \leq C_{t}^{\prime}
$$


Table 1. List of parameters, superscripts, sets and decision variables.

\begin{tabular}{|c|c|}
\hline Notation & Description \\
\hline$n$ & Periodic intervals \\
\hline$C$ & Cost \\
\hline$P^{\prime}$ & Price \\
\hline$u_{p}^{\left(c^{\prime}\right)}$ & Production capacity per unit of product $p$ \\
\hline$u_{p m}^{(m)}$ & Unit $p$ product demand for $m$ components \\
\hline$C_{t}^{\prime}$ & The available production capacity of an assembly plant in the $t$ period \\
\hline$C_{t m s}^{(o)}$ & $\begin{array}{l}\text { The ordering cost of components ordered by the assembly plant at time } t \text { from } \\
\text { supplier } s \text { of } m \text { components }\end{array}$ \\
\hline$C_{t p}^{(p)}$ & The unit cost for the assembly plant to produce product $p$ during time $t$ \\
\hline$Q_{t l p p}^{(p)}$ & $\begin{array}{l}\text { The forecast demand for } p \text { product by } r \text { grade customers in } l \text { area during the } \\
\text { marketing session }\end{array}$ \\
\hline$P_{t l p p}^{\prime(p)}$ & $\begin{array}{l}\text { The unit price of product } p \text { supplied by the assembly plant to } r \text { grade custom- } \\
\text { ers in region } I \text { during time period } t\end{array}$ \\
\hline$P_{t m s}^{\prime(m)}$ & $\begin{array}{l}\text { The assembly plant purchases the unit price of components from } s \text { supplier of } \\
m \text { components in time period } t\end{array}$ \\
\hline$U_{t m s}^{(m)}$ & The maximum supply of $s$ supplier of $m$ component in time period $t$ \\
\hline$I_{m}^{(m)}$ & Initial inventory of assembly plant $m$ components \\
\hline$C_{m}^{(h)}$ & An assembly plant stores the unit cost of $m$ components for a period of time \\
\hline$C_{p}^{(h)}$ & An assembly plant stores the unit cost of $p$ products for a period of time \\
\hline$C_{l p}^{(d)}$ & Unit cost of transportation of product $p$ from the assembly plant to area $l$ \\
\hline \multicolumn{2}{|l|}{ Superscript: } \\
\hline$m$ & Represent component \\
\hline$p$ & Represent product \\
\hline$o$ & Represent order cost \\
\hline$c^{2}$ & Represent production capacity \\
\hline$h$ & Represent inventory cost \\
\hline$d$ & Represent transportation cost \\
\hline \multicolumn{2}{|l|}{ Sets: } \\
\hline$S$ & A set of suppliers, $s \in\left\{1,2,3, \cdots, S_{0}\right\}=S$ \\
\hline$M$ & Component types, $m \in\left\{1,2,3, \cdots, M_{0}\right\}=M$ \\
\hline$P$ & Product type, $\quad p \in\left\{1,2,3, \cdots, P_{0}\right\}=P$ \\
\hline$T$ & Period set, $T=\left\{1,2,3, \cdots, T_{0}\right\}, \quad t \in T, \quad \tau \in T$ \\
\hline$R$ & Customer rating, $\quad r \in\left\{1,2,3, \cdots, R_{0}\right\}=R$ \\
\hline$L$ & A set of region, $l \in\left\{1,2,3, \cdots, L_{0}\right\}=L$ \\
\hline \multicolumn{2}{|c|}{ Decision variables: } \\
\hline$B_{t m}^{(m)}$ & Initial inventory of assembly plant $\mathrm{m}$ components in time period $t$ \\
\hline$E_{t m}^{(m)}$ & The assembly plant's ending inventory of components $\mathrm{m}$ at time $t$ \\
\hline$B_{t p}^{(p)}$ & Initial inventory of $p$ product in time period $t$ \\
\hline$E_{t p}^{(p)}$ & The assembly plant's ending inventory of product $\mathrm{p}$ in time period $t$ \\
\hline$Q_{\text {tms }}^{(m)}$ & $\begin{array}{l}\text { The number of components the assembly plant purchases from } s \text { supplier of } m \\
\text { components in time period } t\end{array}$ \\
\hline$Q_{t p}^{(p)}$ & The number of $p$ products produced by the assembly plant in time period $t$ \\
\hline
\end{tabular}




\section{Continued}

\begin{tabular}{|c|c|}
\hline$Q_{t r r m}^{(m)}$ & $\begin{array}{l}\text { The number of preassigned demand period } \tau \text { by the assembly plant for } r \\
\text { level customers in } t \text { session in the instruction component } \mathrm{m}\end{array}$ \\
\hline$C_{t r \tau}^{\prime}$ & $\begin{array}{l}\text { The quantity of the demand period } \tau \text { preassigned by the assembly plant for } r \\
\text { level customers in } t \text { time period is the capacity of production }\end{array}$ \\
\hline$Q_{\text {trrpp }}^{(p)}$ & $\begin{array}{l}\text { In } t \text { time period, the assembly plant preassigned the number of product } p \text { for } r \\
\text { level customers in } l \text { area in the demand period } \tau\end{array}$ \\
\hline$y_{t m s}^{(m)}$ & $\begin{array}{l}\text { Variable } 0-1 \text {, indicating whether to purchase components from supplier s of } \\
\text { component } \mathrm{m} \text { in time period } t \text {, if it equals to } 1 \text {, then purchase,else not purchase }\end{array}$ \\
\hline
\end{tabular}

Constraint Condition 2: And then it will list some product demand constraint as follows.

$$
\begin{gathered}
\sum_{t \leq \tau} Q_{t l r \tau p}^{(p)} \leq Q_{\tau l r p}^{(p)} \\
Q_{t p}^{(p)}=\sum_{l \in L} \sum_{r \in R} \sum_{\tau \geq t} Q_{t l r \tau p}^{(p)} \\
\sum_{t \geq 2} \sum_{l \in L} \sum_{r \in R} \sum_{\tau \leq t-1} Q_{t l r \tau p}^{(p)}=0
\end{gathered}
$$

Constraint Condition 3: Then it is about some component capability constraints.

$$
\begin{gathered}
\sum_{p \in P} Q_{t p}^{(p)} \cdot u_{p m}^{(m)} \leq \sum_{s \in S} Q_{t m s}^{(m)} \cdot y_{t m s}^{(m)}+B_{t m}^{(m)} \\
Q_{t m s}^{(m)} \leq U_{t m s}^{(m)} \\
\sum_{l \in L} \sum_{p \in P} Q_{t l r \tau}^{(p)} \cdot u_{p m}^{(m)}=Q_{t r m}^{(m)}
\end{gathered}
$$

Constraint Condition 4: Next it will list some component inventory balance constraints.

$$
\begin{gathered}
E_{0 m}^{(m)}=I_{m}^{(m)} \\
B_{t m}^{(m)}=E_{(t-1) m}^{(m)}+\sum_{s \in S} Q_{t m s}^{(m)} \cdot y_{t m s}^{(m)} \\
E_{t m}^{(m)}=B_{t m}^{(m)}-\sum_{p \in P}\left(Q_{t p}^{(p)} \cdot u_{p m}^{(m)}\right)
\end{gathered}
$$

Constraint Condition 5: At last it will give some Product inventory balance constraints.

$$
\begin{gathered}
B_{1 p}^{(p)}=0 \\
E_{t p}^{(p)}=B_{t p}^{(p)}+Q_{t p}^{(p)}-\sum_{i=1}^{t} \sum_{l \in L} \sum_{r \in R} \sum_{\tau=t} Q_{i l r \tau p}^{(p)} \\
B_{t p}^{(p)}=E_{(t-1) p}^{(p)}, t \geq 2 \\
\left\{B_{t m}^{(m)}, E_{t m}^{(m)}, B_{t p}^{(p)}, E_{t p}^{(p)}, Q_{t m s}^{(m)}, Q_{t p}^{(p)}, Q_{t r \tau m}^{(m)}, C_{t r \tau}^{\prime}, Q_{t l r \tau}^{(p)}\right\} \geq 0, \text { And as an integer }
\end{gathered}
$$




$$
y_{\text {tms }}^{(m)} \in\{0,1\}
$$

In the above model, $s \in S ; m \in M ; t \in T ; p \in P ; \tau \in T ; l \in L$. It mainly considers the constraints of production capacity, component supply capacity, inventory and customer product demand.

\section{Results and Discussion}

According to the established ATO supply chain ATP allocation decision model, the relevant data of an assembly manufacturing enterprise was selected for simulation verification. Based on geographical location, the enterprise divides customers into three regions and divides customers in each region into two priorities according to their importance. The production capacity of this enterprise is fixed in each phase. It produces two products, P1 and P2, with a total production capacity of 4500 units. The production capacity required for each product of these two products is 3 units and 2 units respectively. There are three suppliers for each component. The BOM diagram of the two products is shown in Figure 2.

The initial inventory quantity, procurement cost, order cost, inventory cost of each material component and the supply limit of each supplier for each period of time for each material component are shown in Table 2 and Table 3. Relevant cost and supply price information of each product are shown in Table 4 and Table 5. The demand data of the past ten periods of customers of two levels in three regions are shown in Table 6.

Take the exponential smoothing coefficient $\mathrm{a}=0.9$, and the number of periods of quadratic exponential smoothing and quadratic moving average $n=4$. First, use EXCEL software to obtain the predicted product demand of the enterprise in the next five periods, as shown in Table 7. According to the equal weight linear combination prediction model, the demand of customers for the two products in the next five years is obtained, and the production capacity and supplier component supply capacity of the enterprise are combined. Then, the ATP allocation in advance model proposed in this paper is used to allocate the production capacity and components for customers of all levels in all regions in advance. The data in the case is imported into the model and solved by programming with Lingo11.0. The procurement information of components in the next five phases is shown in Table 8 and the allocation information of production capacity in the next five phases is shown in Table 9.
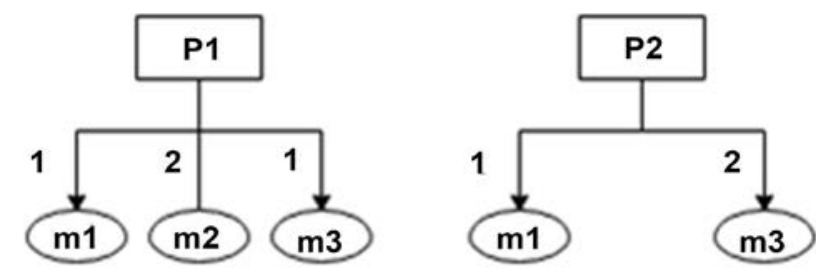

Figure 2. BOM of products. 
Table 2. Procurement costs, ordering costs and component inventory costs for components purchased from supplier S1, S2, and S3.

\begin{tabular}{cccccccc}
\hline \multirow{2}{*}{ M } & \multirow{2}{*}{$\begin{array}{c}\text { Inventory } \\
\text { Cost }\end{array}$} & \multicolumn{3}{c}{ Procurement Cost } & \multicolumn{3}{c}{ Ordering Cost } \\
\cline { 3 - 8 } & S1 & S2 & S3 & S1 & S2 & S3 \\
\hline m1 & 1 & 250 & 270 & 300 & 2000 & 2500 & 3000 \\
m2 & 1 & 200 & 230 & 240 & 2500 & 3000 & 2500 \\
m3 & 2 & 180 & 200 & 220 & 3000 & 3500 & 3000 \\
\hline
\end{tabular}

Table 3. Initial inventory of component $\mathrm{M}$ and component supply limit tables of supplier S1, S2 and S3.

\begin{tabular}{ccccc}
\hline & & \multicolumn{3}{c}{ Component Supply Limit } \\
\cline { 3 - 5 } M & Initial Inventory & $\mathrm{S} 1$ & $\mathrm{~S} 2$ & $\mathrm{~S} 3$ \\
\hline $\mathrm{m} 1$ & 300 & 1300 & 500 & 300 \\
$\mathrm{~m} 2$ & 200 & 1200 & 400 & 300 \\
$\mathrm{~m} 3$ & 400 & 2000 & 500 & 500 \\
\hline
\end{tabular}

Table 4. Production cost, Inventory cost and Transportation cost of Product P.

\begin{tabular}{cccccc}
\hline P & $\begin{array}{c}\text { Production } \\
\text { Cost }\end{array}$ & Inventory Cost & L1 & L2 & L3 \\
\hline P1 & 30 & 2 & 2 & 3 & 4 \\
P2 & 24 & 2 & 2 & 3 & 4 \\
\hline
\end{tabular}

Table 5. Supply prices of products to different rate customers in different regions.

\begin{tabular}{ccccccc}
\hline & \multicolumn{5}{c}{ Supply prices of Products } \\
\cline { 2 - 6 } & L1R1 & L1R2 & L2R1 & L2R2 & L3R1 & L3R2 \\
\hline P1 & 2000 & 1200 & 2000 & 1200 & 2000 & 1200 \\
P2 & 5000 & 3750 & 5000 & 3750 & 5000 & 3750 \\
\hline
\end{tabular}

Table 6. Historical demand of the first 1-10 periods of the customers.

\begin{tabular}{ccccccccccccc}
\hline \multirow{2}{*}{ Region } & R & P & \multicolumn{10}{c}{ Historical Demand } \\
\cline { 3 - 11 } & & & 1 & 2 & 3 & 4 & 5 & 6 & 7 & 8 & 9 & 10 \\
\hline \multirow{2}{*}{ L1 } & R & P1 & 159 & 179 & 163 & 180 & 168 & 170 & 160 & 157 & 173 & 162 \\
& 1 & P2 & 135 & 138 & 156 & 136 & 150 & 159 & 146 & 139 & 149 & 140 \\
& R & P1 & 99 & 117 & 123 & 119 & 102 & 116 & 97 & 90 & 106 & 125 \\
& 2 & P2 & 118 & 95 & 90 & 105 & 113 & 109 & 91 & 92 & 119 & 90 \\
& R & P1 & 198 & 170 & 196 & 178 & 179 & 196 & 197 & 194 & 185 & 194 \\
& 1 & P2 & 184 & 184 & 190 & 185 & 185 & 169 & 174 & 171 & 168 & 151 \\
& R & P1 & 99 & 98 & 122 & 124 & 95 & 130 & 110 & 122 & 115 & 110 \\
& 2 & P2 & 114 & 123 & 111 & 102 & 98 & 104 & 99 & 90 & 94 & 121 \\
& R & P1 & 180 & 176 & 215 & 173 & 207 & 199 & 196 & 170 & 181 & 187 \\
& 1 & P2 & 150 & 194 & 146 & 176 & 168 & 184 & 186 & 175 & 167 & 151 \\
& R & P1 & 116 & 130 & 102 & 118 & 123 & 130 & 110 & 110 & 108 & 118 \\
& 2 & P2 & 106 & 114 & 96 & 90 & 108 & 109 & 109 & 96 & 109 & 117 \\
\hline
\end{tabular}


Table 7. The result of equal weight combination prediction model for the next five periods.

\begin{tabular}{|c|c|c|c|c|c|c|c|}
\hline \multirow{2}{*}{ Regions } & \multirow{2}{*}{$\mathrm{R}$} & \multirow{2}{*}{$\mathrm{P}$} & \multicolumn{5}{|c|}{ Forecast Demand } \\
\hline & & & 1 & 2 & 3 & 4 & 5 \\
\hline \multirow{4}{*}{ L1 } & \multirow{2}{*}{$\mathrm{R} 1$} & $\mathrm{P} 1$ & 172 & 174 & 176 & 178 & 180 \\
\hline & & $\mathrm{P} 2$ & 145 & 150 & 154 & 158 & 163 \\
\hline & \multirow{2}{*}{$\mathrm{R} 2$} & $\mathrm{P} 1$ & 111 & 108 & 105 & 102 & 99 \\
\hline & & P2 & 103 & 105 & 108 & 110 & 112 \\
\hline \multirow{4}{*}{ L2 } & \multirow{2}{*}{$\mathrm{R} 1$} & P1 & 183 & 181 & 179 & 177 & 175 \\
\hline & & P2 & 188 & 192 & 197 & 201 & 205 \\
\hline & \multirow{2}{*}{ R2 } & $\mathrm{P} 1$ & 113 & 115 & 117 & 119 & 121 \\
\hline & & $\mathrm{P} 2$ & 106 & 100 & 93 & 86 & 80 \\
\hline \multirow{4}{*}{ L3 } & \multirow{2}{*}{$\mathrm{R} 1$} & $\mathrm{P} 1$ & 190 & 195 & 201 & 206 & 211 \\
\hline & & $\mathrm{P} 2$ & 175 & 183 & 190 & 198 & 206 \\
\hline & \multirow{2}{*}{$\mathrm{R} 2$} & P1 & 117 & 119 & 120 & 121 & 123 \\
\hline & & P2 & 101 & 98 & 96 & 94 & 92 \\
\hline
\end{tabular}

Table 8. Next five periods of component procurement information.

\begin{tabular}{|c|c|c|c|c|c|c|}
\hline \multirow{2}{*}{ M } & \multirow{2}{*}{$S$} & \multicolumn{5}{|c|}{ Purchase Quantity } \\
\hline & & 1 & 2 & 3 & 4 & 5 \\
\hline \multirow{3}{*}{$\mathrm{m} 1$} & S1 & 1300 & 1300 & 1300 & 1300 & 1300 \\
\hline & S2 & 473 & 500 & 500 & 0 & 404 \\
\hline & S3 & 0 & 0 & 0 & 0 & 0 \\
\hline \multirow{3}{*}{$\mathrm{m} 2$} & S1 & 1200 & 1200 & 1200 & 1200 & 1200 \\
\hline & S2 & 400 & 400 & 400 & 400 & 400 \\
\hline & S3 & 0 & 260 & 300 & 0 & 216 \\
\hline \multirow{3}{*}{$\mathrm{m} 3$} & S1 & 2000 & 2000 & 2000 & 2000 & 2000 \\
\hline & S2 & 466 & 500 & 500 & 500 & 500 \\
\hline & S3 & 0 & 0 & 0 & 0 & 0 \\
\hline
\end{tabular}

Table 9. Next five periods of capacity allocation information.

\begin{tabular}{cccc}
\hline Periods & Allocation Periods in Advance & R1 & R2 \\
\hline$\tau$ & $=1$ & 2651 & 1643 \\
$\tau$ & $=2$ & 0 & 206 \\
$\tau$ & $=3$ & 0 & 0 \\
$\tau$ & $=4$ & 0 & 0 \\
$\tau$ & $=5$ & 0 & 0 \\
& $\tau=2$ & 2700 & 1426 \\
& $\tau=3$ & 165 & 204 \\
2 & $\tau=4$ & 0 & 0 \\
& $\tau=5$ & 3 & 0 \\
& $\tau=3$ & 2585 & 1416 \\
& $\tau=4$ & 309 & 0 \\
& $\tau=5$ & 0 & 118 \\
& $\tau=4$ & 2488 & 1606 \\
& $\tau=5$ & 0 & 6 \\
5 & $\tau=5$ & 2843 & 1473 \\
\hline
\end{tabular}


For the example in this paper, it can be found from Table 7 that, for the manufacturer, the fluctuation range of product demand of customers at all levels of the region in the next five periods is small. As can be seen from Table 8, in the next five periods, all components need to be purchased from multiple suppliers, so the enterprise should make a reasonable procurement plan and communicate with corresponding suppliers about procurement issues as early as possible. It can be seen from Table 9 that the production capacity of the enterprise in the next five periods is sufficient in the short term, and the vacant production capacity is not much. If the enterprise has new production planning in the future, it should consider adjusting the production capacity accordingly.

After the ATP allocation decision, the enterprise can make a reasonable procurement plan and arrange its production capacity according to the needs of different levels of customers in different regions, so as to quickly allocate customer demands, so as to maintain the relationship between the enterprise and high-quality customers and ensure the profit and long-term development of the enterprise. The total customer demand is 8680 units of products. In the case of multiple supply sources of components, the enterprise can provide 8677 unit products, the order satisfaction rate is $99.85 \%$, and the total profit of the enterprise is 2005.77 million yuan. At the same time, components with multiple supply sources not only reduce the risk of supply chain, but also make full use of enterprise production capacity, improve enterprise efficiency and customer service level.

\section{Conclusion}

In ATP allocation in advance model, this paper is on the basis of the results of predict demand, considering production capacity, component supply, customer level, transportation cost, storage cost and other constraints, combined with the distribution rules for the ATP level customers in different times allocated material components, to speed up the efficiency of enterprise order allocation and enhance the reliability of the enterprise order commitments. In the process of order allocation, whether the ATP allocation is reasonable will have a direct impact on the order performance rate and corporate income, as well as the responsiveness and competitiveness of enterprises to customer orders. Therefore, it is of profound theoretical and practical significance to discuss how to reasonably and scientifically allocate ATP.

\section{Conflicts of Interest}

The authors declare no conflicts of interest regarding the publication of this paper.

\section{References}

[1] Zheng, D., Chen, H. and Huang, Y. (2013) Supply Chain Commitment Allocation Decision Model. Journal of Shanghai Maritime University, 3, 1-4. 
[2] Raghavan, N.R.S. and Dulluri, S. (2017) Revenue Management via Multi-Product Available to Promise. Journal of Industrial and Management Optimization, 3, 457-479. https://doi.org/10.3934/jimo.2007.3.457

[3] Chen, J., Chen, H. and Ni, Y. (2014) Order Allocation Model Based on Flexible Combination Strategy. Industrial Engineering and Management, 16, 84-89.

[4] Gao, L., Xu, S.H. and Ball, M.O. (2015) Managing an Available-to-Promise Assembly System with Dynamic Short-Term Pseudo-Order Forecast. Management Science, 58, 770-790. https://doi.org/10.1287/mnsc.1110.1442

[5] Ding, S. and Chen, H. (2015) Supply Chain Commitment Allocation Decision Based on Customer Classification. Journal of Wuhan University of Technology (Social Science Edition), 25, 334-338.

[6] Jung, H. (2016) An Available-to-Promise Model Considering Customer Priority and Variance of Penalty Costs. The International Journal of Advanced Manufacturing Technology, 49, 369-377. https://doi.org/10.1007/s00170-009-2389-9

[7] Gössinger, R.K. (2014) How to Increase Robustness of Capable-to-Promise. In: Lübbecke, M., Koster, A., Eds., Operations Research Proceedings 2014, Springer International Publishing, Berlin, 213-219.

https://doi.org/10.1007/978-3-319-28697-6_30

[8] Zhang, J., Qin, W. and Wang, W. (2014) An Available-to-Promise Model for Periodical Order Promising. In: LISS 2014, Springer Berlin Heidelberg, Berlin, 167-171. https://doi.org/10.1007/978-3-662-43871-8_26

[9] Cheng, C.B. and Wu, M.T. (2014) Customer Order Fulfillment Based on a Rolling Horizon Available-to-Promise Mechanism: Solution by Fuzzy Approach and Genetic Algorithm. In: Filev, D., et al., Eds., Advances in Intelligent Systems and Computing, Springer International Publishing, Switzerland, 477-488. https://doi.org/10.1007/978-3-319-11310-4_41

[10] Lin J.T., Hong I.H., Wu C.H., et al. (2013) A Model for Batch Available-To-Promise in Order Fulfillment Processes for TFT-LCD Production Chains. Computers \& Industrial Engineering, 59, 720-729.

[11] Alemany, M.M.E., Lario, F.C., Ortiz, A., et al. (2013) Available-to-Promise Modeling for Multi-Plant Manufacturing Characterized by Lack of Homogeneity in the Product: An Illustration of a Ceramic Case. Applied Mathematical Modelling, 37, 3380-3398. https://doi.org/10.1016/j.apm.2012.07.022

[12] Chen-Ritzo, C.H., Ervolina, T., Harrison, T.P., et al. (2014) Component Rationing for Available-to-Promise Scheduling in Configure-to-Order Systems. European Journal of Operational Research, 211, 57-65.

https://doi.org/10.1016/j.ejor.2010.11.006

[13] Grillo, H., Alemany, M. and Ortiz, A. (2016) Modelling Pricing Policy Based on Shelf-Life of Non-Homogeneous Available-to-Promise in Fruit Supply Chains. In: Afsarmanesh, H., Camarinha-Matos, L. and Lucas-Soares, A., Eds., IFIP Advances in Information and Communication Technology, Springer, Cham, 608-617. https://doi.org/10.1007/978-3-319-45390-3_52

[14] Rabbani, M., Sadri, S., Manavizadeh, N., et al. (2015) A Novel Bi-Level Hierarchy towards Available-to-Promise in Mixed-Model Assembly Line Sequencing Problems. Engineering Optimization, 47, 947-962.

https://doi.org/10.1080/0305215X.2014.933823 